\title{
Chronic Hypobaric Hypoxia Increases Isolated Rat Fast-Twitch and Slow-Twitch Limb Muscle Force and Fatigue
}

\author{
R. EL-KHOURY ${ }^{1}$, A. BRADFORD ${ }^{1}$, K. D. O'HALLORAN ${ }^{2}$ \\ ${ }^{1}$ Department of Physiology and Medical Physics, Royal College of Surgeons in Ireland, \\ St. Stephen's Green, Dublin, Ireland, ${ }^{2}$ UCD School of Medicine and Medical Science, University \\ College Dublin, Dublin, Ireland
}

Received December 16, 2010

Accepted November 29, 2011

On-line January 31, 2012

\section{Summary}

Chronic hypoxia alters respiratory muscle force and fatigue, effects that could be attributed to hypoxia and/or increased activation due to hyperventilation. We hypothesized that chronic hypoxia is associated with phenotypic change in non-respiratory muscles and therefore we tested the hypothesis that chronic hypobaric hypoxia increases limb muscle force and fatigue. Adult male Wistar rats were exposed to normoxia or hypobaric hypoxia $(P B=450 \mathrm{~mm} \mathrm{Hg})$ for 6 weeks. At the end of the treatment period, soleus (SOL) and extensor digitorum longus (EDL) muscles were removed under pentobarbitone anaesthesia and strips were mounted for isometric force determination in Krebs solution in standard water-jacketed organ baths at $25^{\circ} \mathrm{C}$. Isometric twitch and tetanic force, contractile kinetics, forcefrequency relationship and fatigue characteristics were determined in response to electrical field stimulation. Chronic hypoxia increased specific force in SOL and EDL compared to age-matched normoxic controls. Furthermore, chronic hypoxia decreased endurance in both $\operatorname{limb}$ muscles. We conclude that hypoxia elicits functional plasticity in limb muscles perhaps due to oxidative stress. Our results may have implications for respiratory disorders that are characterized by prolonged hypoxia such as chronic obstructive pulmonary disease (COPD).

\section{Key words}

Hypoxia • Skeletal muscle • Fatigue

\section{Corresponding author}

K. D. O'Halloran, Department of Physiology, University College Cork, Western Gateway Building, Western Road, Cork, Ireland. E-mail: K.OHalloran@ucc.ie

\section{Introduction}

Chronic hypoxia occurs in humans in a variety of circumstances, including respiratory disease and exposure to altitude. The effects of chronic continuous hypoxia on skeletal muscle structure have been well investigated. In rats, limb muscles generally show a transition from slow to fast phenotype (Sillau and Branchero 1977, Itoh et al. 1990, Bigard et al. 1991, Ishihara et al. 1995, Mortola and Naso 1995, Faucher et al. 2005), although Shiota et al. (2004) observed the opposite shift and no change has been observed in some muscles (Bigard et al. 1991, Ishihara et al. 1995, Shiota et al. 2004). Chronic hypoxia has also been shown to cause angiogenesis in skeletal muscle (Smith and Marshall 1999). In humans, limb muscle fibre diameter is reduced but fibre type is unaffected by altitude exposure (Green et al. 1989, MacDougall et al. 1991) and recently Edwards et al. (2009) reported atrophy in skeletal muscle with maintained function. There is good evidence that chronic altitude exposure leads to a decrease in mitochondrial function and aerobic metabolism (Green et al. 1989, Hoppeler et al. 2003, Murray 2009). Patients with chronic obstructive pulmonary disease (COPD) have reduced aerobic metabolism in limb muscles (Gertz et al. 1977) and they show evidence of fibre atrophy and a higher proportion of fast fibres (Hildebrand et al. 1991, Whittom et al. 1998, Debigare et al. 2003), which could be influenced by a number of factors including hypokinesis and chronic hypoxia (Man et al. 2009).

Functional studies in humans exposed to 
altitude, examining muscle contraction and endurance have been inconsistent in their findings (Garner et al. 1990, Fulco et al. 1994, Kayser et al. 1994, Caquelard et al. 2000) but there is evidence of increased muscle fatigability after altitude exposure (Caquelard et al. 2000) and in COPD (Zattara-Hartmann et al. 1995). We previously reported that chronic hypobaric hypoxia alters isolated rat respiratory muscle force and fatigue (El-Khoury et al. 2003). We have also demonstrated that chronic intermittent hypoxia - modelling human sleep apnoea - alters respiratory and limb muscle endurance (McGuire et al. 2002a,b, 2003, Bradford et al. 2005, Dunleavy et al. 2008). This suggests a generalized effect of hypoxia on skeletal muscle. Because of the increased activity in the respiratory muscles of rats exposed to chronic continuous and chronic intermittent hypoxia due to hyperventilation - a 'training' effect i.e. activitydependent plasticity may at least in part explain functional changes in active muscles exposed to chronic hypoxia. We speculated that 6 weeks of chronic hypobaric hypoxia, sufficient to cause functional plasticity in respiratory muscle (El-Khoury et al. 2003), would also elicit widespread effects on skeletal muscle function. Therefore, the present study sought to determine the effects of chronic hypobaric hypoxia on rat slowtwitch (soleus, SOL) and fast-twitch (extensor digitorum longus, EDL) muscle contractile and endurance properties. We hypothesized that chronic hypoxia increases limb muscle fatigue.

\section{Methods}

\section{Animal care}

All procedures were performed in accordance with National and European legislation under licence from the Irish Government Department of Health and Children with additional institutional approval from the Royal College of Surgeons in Ireland animal research ethics committee. Adult male Wistar rats ( $\sim 10$ weeks old $)$ were randomly assigned to control $(\mathrm{N}=12)$ or hypoxia $(\mathrm{N}=15)$ groups. The hypoxia group was placed in a hypobaric chamber at an ambient pressure of $450 \mathrm{~mm} \mathrm{Hg}$ (inspired $\mathrm{PO}_{2}=85 \mathrm{~mm} \mathrm{Hg}$ ). Decompression and recompression were performed gradually over 1-2 hours. Recompression for cage cleaning and food and water replenishment occurred every 2-3 days. Agematched control rats remained at sea-level pressure in the same room in parallel.

\section{In vitro muscle preparation}

After 6 weeks, animals were anaesthetized with an intra-peritoneal injection of sodium pentobarbitone (70 mg/kg body weight). A midline cervical incision was made and a tracheal cannula inserted through which the animals could breathe spontaneously. Whole SOL and EDL muscles with tendinous insertions intact were removed. Blood samples were taken for detemination of haematocrit. Animals were euthanized with an overdose of anaesthetic. After removal, the muscles were placed in a bath at room temperature containing continuously gassed $\left(95 \% \mathrm{O}_{2} / 5 \% \mathrm{CO}_{2}\right) \mathrm{Krebs}$ solution. The solution contained in $\mathrm{mM}$ : $\mathrm{NaCl} 120, \mathrm{KCl} 5, \mathrm{Ca}^{2+}$ gluconate 2.5, $\mathrm{MgSO}_{4}$ 1.2, $\mathrm{NaH}_{2} \mathrm{PO}_{4}$ 1.2, $\mathrm{NaHCO}_{3} 25$ and glucose 11.5. Strips of muscle were prepared and then suspended vertically in Krebs solution in water-jacketed organ baths at $25{ }^{\circ} \mathrm{C}(\mathrm{pH} 7.4)$. The physiological stability of rat skeletal muscle in vitro is temperature-dependent and stability for muscle strips of 1-2 mm diameter is better at $25{ }^{\circ} \mathrm{C}$ compared to the in vivo temperature of $37{ }^{\circ} \mathrm{C}$ (Segal and Faulkner 1985). The strips were suspended between a pair of platinum electrodes, with the base fixed to an immobile hook and the other end tied to an isometric force transducer. The position of the force transducer could be adjusted by a micro-positioner, thus altering preload.

\section{Protocol}

After an equilibration period of $30 \mathrm{~min}$, the optimal length (i.e. muscle length producing maximal isometric twitch force) was determined. The muscle was held at this length for the remainder of the experiment. The single isometric twitch force, contraction time, halfrelaxation time, force-frequency relationship and fatigue characteristics of the muscles were determined in response to electrical field stimulation and were recorded using a commercial data acquisition system and stored for later analysis on a computer. First, a single twitch was elicited (supra-maximal voltage, $1 \mathrm{~ms}$ duration). Twitch force, contraction time (time to peak force) and half-relaxation time (time for peak force to decay by $50 \%$ ) were determined. Next, force-frequency relationship was determined by sequentially stimulating the muscle strips at 10, 20, 30, 40, 50, 60, 70, 80, 90 and $100 \mathrm{~Hz}$ for $300 \mathrm{~ms}$ at each stimulus frequency allowing a 2 min recovery interval between each stimulus. Ten min following this forcefrequency protocol, fatigue was induced by stimulation at $40 \mathrm{~Hz}$ with $300 \mathrm{~ms}$ trains at $0.5 \mathrm{~Hz}$ for $5 \mathrm{~min}$. Force was measured at $1 \mathrm{~min}$ intervals during fatigue. 


\section{Data analysis}

Specific force was calculated in $\mathrm{N} / \mathrm{cm}^{2}$ of muscle cross-sectional area. The latter was approximated by weighing the muscle strip at the end of the experimental protocol and dividing this by the product of optimal length and muscle density (assumed to be $1.056 \mathrm{~g} / \mathrm{cm}^{3}$ ). The force transducers were calibrated using known weights. The contraction time and half-relaxation time were measured as indices of isometric twitch kinetics. For the force-frequency relationship, the values were normalized by expressing force at each of the different stimulus frequencies as a percentage of the maximum tetanic force developed during each trial. For the fatigue protocol, values were normalized by expressing the force generated at each 1 min time point, as a percentage of the initial force at the beginning of the fatigue trial. Absolute and normalized values are expressed as mean \pm S.E.M. Statistical comparisons between control and hypoxia groups were performed using Student's $t$ test or oneway ANOVA and Fischer's least significant difference test as appropriate with $\mathrm{P}<0.05$ taken as significant in all tests.

\section{Results}

\section{General}

The body weight of the hypoxic rats was significantly lower than control animals after 6 weeks ( $308 \pm 8$ g vs. $275 \pm 5$ g, control vs. hypoxia, $\mathrm{P}<0.05$, Student's $t$ test). Furthermore, the haematocrit was significantly higher in the hypoxia group $(51 \pm 2 \%$ vs. $64 \pm 2 \%$, mean \pm S.E.M., control vs. hypoxia, $\mathrm{P}<0.05$, Student's $t$ test).

\section{Soleus}

Chronic hypobaric hypoxia caused a significant increase in twitch and peak tetanic force (Table 1). Contraction time was unaffected by hypoxia, but halfrelaxation time was significantly prolonged (Table 1). Chronic hypoxia had no effect on the force-frequency relationship (Fig. 1A) but decreased SOL muscle endurance (Fig. 1B). Fatigue was significantly decreased after 4 and 5 min of the repeated muscle stimulation trial; one can see from Figure 1B that the fatigue curves for normoxic and chronic hypoxic muscles diverge considerably after 4 min of stimulation. The magnitude of the decline in fatigue tolerance in hypoxic muscles would presumably have continued to increase with extended time.
Table 1. Contractile properties of soleus (SOL) and extensor digitorum longus (EDL) muscles from normoxic and chronically hypoxic rats.

\begin{tabular}{lcc}
\hline & Normoxia & Hypoxia \\
\hline SOL & $(\mathrm{N}=12)$ & $(\mathrm{N}=14)$ \\
Twitch force $\left(\mathrm{N} / \mathrm{cm}^{2}\right)$ & $2.0 \pm 0.2$ & $2.8 \pm 0.2^{*}$ \\
Contraction time $(\mathrm{ms})$ & $72 \pm 3$ & $70 \pm 3$ \\
Half-relaxation time $(\mathrm{ms})$ & $70 \pm 4$ & $97 \pm 4^{*}$ \\
Tetanic force $\left(\mathrm{N} / \mathrm{cm}^{2}\right)$ & $9.0 \pm 12.1$ & $12.1 \pm 0.9^{*}$ \\
Twitch/Tetanus ratio & $0.23 \pm 0.03$ & $0.24 \pm 0.01$ \\
& $(\mathrm{~N}=10)$ & $(\mathrm{N}=15)$ \\
EDL & $2.5 \pm 0.3$ & $3.8 \pm 0.4^{*}$ \\
Twitch force $\left(\mathrm{N} / \mathrm{cm}^{2}\right)$ & $32 \pm 2$ & $33 \pm 2$ \\
Contraction time $\left(\mathrm{ms}^{2}\right)$ & $22 \pm 6$ & $25 \pm 2$ \\
Half-relaxation time $(\mathrm{ms})$ & $8.5 \pm 1.8$ & $10.9 \pm 1.1$ \\
Tetanic force $\left(\mathrm{N} / \mathrm{cm}^{2}\right)$ & $0.35 \pm 0.04$ & $0.35 \pm 0.01$ \\
Twitch/Tetanus ratio & & \\
\hline
\end{tabular}

Values are mean \pm S.E.M. * indicates significant difference from corresponding value in normoxic control rats; $\mathrm{P}<0.05$, Student's $t$ test.

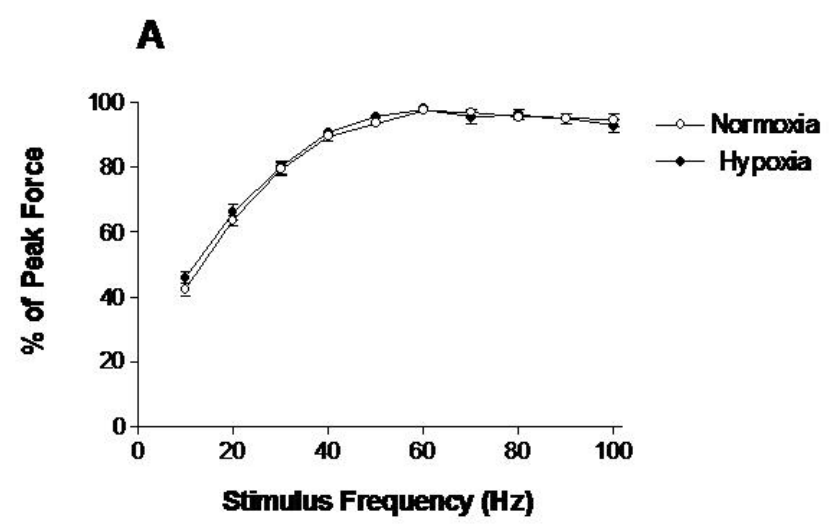

B

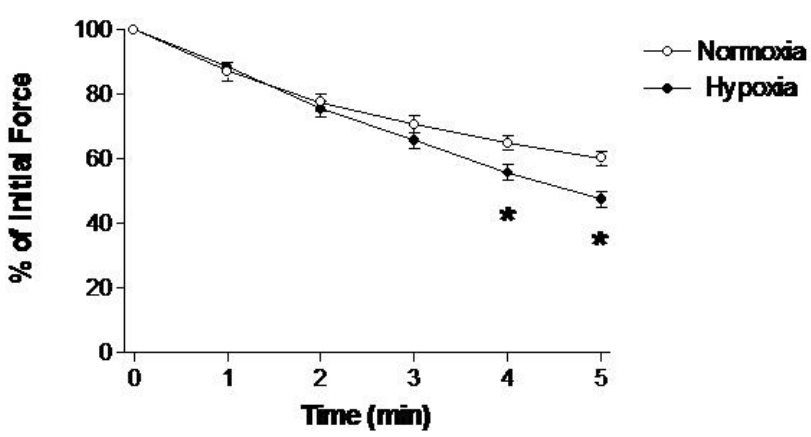

Fig. 1. Force-frequency relationship (A) and fatigue characteristics (B) for soleus muscle in normoxic $(\mathrm{N}=12)$ and chronically hypoxic $(\mathrm{N}=14)$ rats. Values are mean \pm S.E.M. In $\mathbf{A}$, values are expressed at each stimulus frequency as a percentage of the peak tetanic force developed during the trial. In B, values are expressed at each time point as a percentage of the initial force at the beginning of the fatigue trial (time 0$). *$ indicates a significant difference from normoxia (control); $\mathrm{P}<0.05$, ANOVA. 


\section{Extensor digitorum longus}

Chronic hypoxia caused a significant increase in twitch force with no effect on contractile kinetics (Table 1). Peak tetanic force was increased but this did not achieve statistical significance (Table 1). Chronic hypoxia caused a significant left-shift in the forcefrequency relationship (Fig. 2A), which was different to the response seen in SOL (Fig. 1A). Chronic hypoxia significantly decreased EDL endurance (Fig. 2B). This was significant after $3 \mathrm{~min}$ of the fatigue trial. Unlike SOL, the increased fatigue in hypoxic muscles appeared to have reached a plateau within the $5 \mathrm{~min}$ time trial.

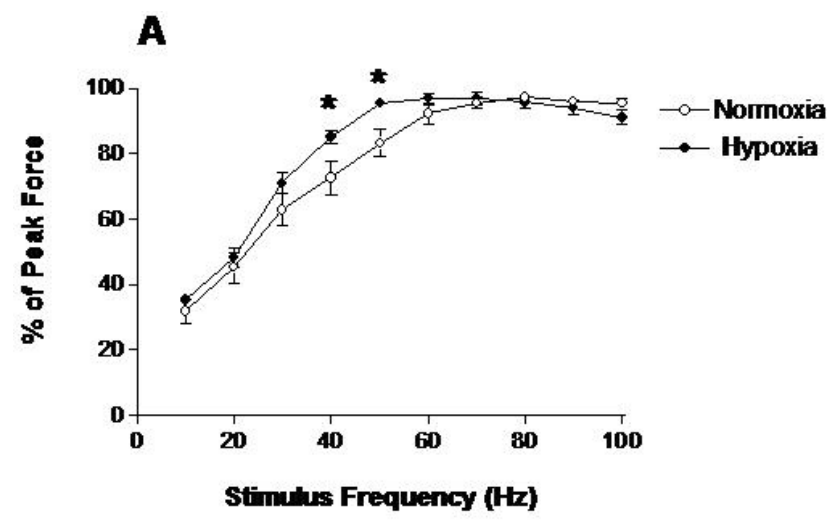

B

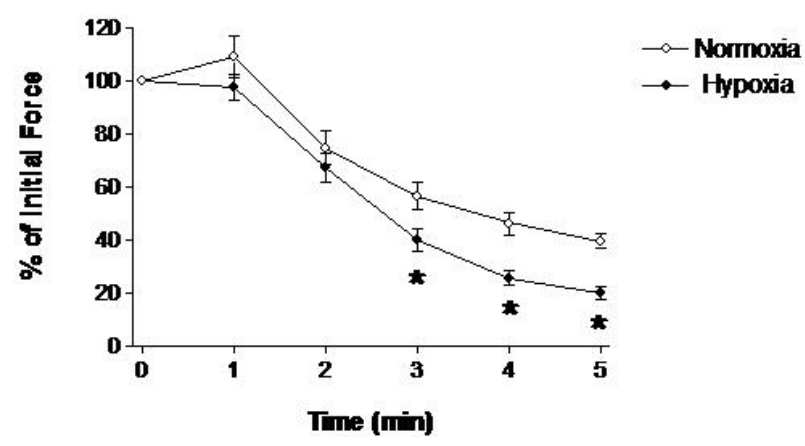

Fig. 2. Force-frequency relationship (A) and fatigue characteristics (B) for extensor digitorum longus muscle in normoxic $(\mathrm{N}=10)$ and chronically hypoxic $(\mathrm{N}=15)$ rats. Values are mean \pm S.E.M. In $\mathbf{A}$, values are expressed at each stimulus frequency as a percentage of the peak tetanic force developed during the trial. In B, values are expressed at each time point as a percentage of the initial force at the beginning of the fatigue trial (time 0 ). ${ }^{*}$ indicates a significant difference from normoxia (control); $\mathrm{P}<0.05$, ANOVA.

\section{Discussion}

The main finding of this study is that chronic hypobaric hypoxia increases specific force and fatigue in rat slow-twitch and fast-twitch limb muscles; however differences in the effects of hypoxia on SOL and EDL were noted. Surprisingly little is known about the effects of chronic hypoxia on skeletal muscle contractile and endurance characteristics. In humans, chronic hypoxia has generally been reported to have little effect on force and fatigue (Garner et al. 1990, Fulco et al. 1994, Kayser et al. 1994), although forearm force and endurance were reduced after 32 days of high altitude exposure (Caquelard et al. 2000). Regarding the chronic hypoxia of respiratory disease, chronic hypoxaemic patients are reported to have reduced respiratory and limb muscle force and endurance (Zattara-Hartmann et al. 1995, Polkey et al. 1996), but this may relate to other factors associated with chronic respiratory disease (e.g. hyperinflation/loading, fibre atrophy, inflammation, nutritional status, hypokinesis etc) rather than hypoxia per se (Man et al. 2009). There have been relatively few studies of the effects of chronic hypoxia on isolated skeletal muscle function (Itoh et al. 1990, Shiota et al. 2004, Faucher et al. 2005). Using isolated in vitro muscle preparations allows the accurate determination of muscle functional characteristics independent of a number of potentially confounding variables in vivo such as: oxygen and nutrient supply, neuromuscular excitability, and muscle cross-sectional area, temperature and initial fibre length. We acknowledge too however that there are significant limitations associated with isolated muscle preparations. Prolonged incubation of muscle bundles in Krebs may have led to tissue swelling; we did not measure tissue mass at the start of the protocol for comparison to mass at the end of the study so we cannot rule out this possibility. Moreover, we assume that functional changes in vitro are reflective of muscle performance in vivo but this may not necessarily be the case. Itoh et al. (1990) reported that chronic hypobaric hypoxia (10 weeks at a simulated altitude of $4.000 \mathrm{~m}$ ) in rats resulted in a reduction in force and fatigue in the EDL muscle but SOL muscle was unaffected. Faucher et al. (2005) reported that chronic hypoxia $\left(\mathrm{FiO}_{2}=0.10\right.$ for 4 weeks) increased SOL muscle force but decreased EDL force and endurance whilst others reported that chronic hypobaric hypoxia (6 weeks at a simulated altitude of $5.000 \mathrm{~m}$ ) had no effect on limb muscle force or fatigue (Shiota et al. 2004). In single fibre studies, SOL muscle force was decreased an effect attributed to decreased myosin content (Degens et al. 2010). One plausible explanation for the different findings in these studies may be differences in the duration and intensity of chronic hypoxia as well as different methodological approaches. 
We have recently shown that respiratory muscle remodelling during sustained hypoxia is time-dependent (McMorrow et al. 2011). Moreover, the effects of chronic hypoxia on respiratory muscle endurance are dependent on the severity of the hypoxic challenge and the intrinsic structural and metabolic properties of the muscles studied (El-Khoury et al. 2003, McMorrow et al. 2011).

In the present study, chronic hypoxia increased force and fatigue of both SOL and EDL muscles. It is possible that fibre-type transition towards glycolytic metabolism drives this functional change. Chronic hypoxia has been shown to cause an increase in fast fibres in the EDL and plantaris muscle (Bigard et al. 1991), in anterior tibialis and gastrocnemius (Sillau and Banchero 1977) and in SOL if hypoxic exposure occurred during development (Ishihara et al. 1995) but not during adult life (Sillau and Banchero 1977, Bigard et al. 1991, Ishihara et al. 1995). Hypoxia-induced inhibition of growth-related transitions in fibre phenotype in limb muscles has been proposed (Faucher et al. 2005). The increase in force observed in the present experiments would be consistent with a transition to fast fibres since fast fibres generate more force than slow fibres. The increase in muscle fatigue would also be consistent with a transition to fast fibres since the latter have low fatigue resistance. However, in a recent study (McMorrow et al. 2011) we showed that chronic hypobaric hypoxia does not alter fibre distribution or oxidative capacity in rat limb muscle. At the molecular level, one might speculate that myostatin is implicated in hypoxic adaptation in skeletal muscle (Hayot et al. 2011). We suggest that redox modulation of muscle function underlies the functional changes reported herein. Reactive oxygen species (ROS) are important signalling molecules in muscle but oxidative stress is implicated in muscle fatigue. We have shown that respiratory muscle dysfunction in a rat model of chronic intermittent hypoxia is prevented by antioxidant treatment (Skelly et al. 2012).
It would be interesting to explore the effects of antioxidant supplementation on skeletal muscle function in sustained hypoxia.

The observed changes in muscle function in both slow-twitch and fast-twitch limb muscles suggest a widespread effect of chronic hypoxia on skeletal muscle. Recently, a study of the effect of acute hypoxia on fatigue development in rat limb muscles studied in vivo clearly demonstrated that hypoxia induces greater fatigue in hindlimb muscle composed primarily of fibres with low oxidative capacity compared with that of a muscle with a more oxidative phenotype (Howlett and Hogan 2007). Concomitant with this apparent increased hypoxic sensitivity in fast muscle were greater increases in cellular metabolites such as lactate, hydrogen ions, inorganic phosphate, and free ADP and AMP (Howlett and Hogan 2007), all of which are known to correlate with skeletal muscle fatigue (Allen et al. 1995, Westerblad and Allen 2003). However, in vivo, differential effects of hypoxia on muscle function may also be related to differences in oxygen delivery and uptake between muscle groups. The results of our study suggest that at the level of the muscle fibre, chronic hypoxia causes phenotypic plasticity that is qualitatively similar in limb muscles of different structural make-up, though it is interesting to note that the magnitude of the hypoxia-induced increase in muscle fatigue was greater in the fast EDL muscle. We conclude that chronic systemic hypoxaemia has widespread effects on skeletal muscle. Our results have relevance to respiratory disorders that are characterized by prolonged hypoxia such as COPD where limb muscle fatigue is known to occur.

\section{Conflict of Interest}

There is no conflict of interest.

\section{Acknowledgements}

Supported by the Royal College of Surgeons in Ireland.

\section{References}

ALLEN D, LANNERGREN J, WESTERBLAD H: Muscle cell function during prolonged activity: cellular mechanisms of fatigue. Exp Physiol 80: 497-527, 1995.

ALLEN DG, WESTERBLAD H: Role of phosphate and calcium stores in muscle fatigue. J Physiol 536: 657-665, 2001.

BIGARD AX, BRUNET A, GUEZENNEC CY, MONOD H: Skeletal muscle changes after endurance training at high altitude. J Appl Physiol 71: 2114-2121, 1991. 
BRADFORD A, MCGUIRE M, O'HALLORAN KD: Does episodic hypoxia affect upper airway dilator muscle function? Implications for the pathophysiology of obstructive sleep apnoea. Respir Physiol Neurobiol 147: 223-234, 2005.

CAQUELARD F, BURNET H, TAGLIARINE F, CAUCHY E, RICHALET JP, JAMMES Y: Effects of prolonged hypobaric hypoxia on human skeletal muscle function and electromyographic events. Clin Sci 98: 329-337, 2000.

DEBIGARE R, COTE CH, HOULD FS, LEBLANC P, MALTAIS F: In vitro and in vivo contractile properties of the vastus lateralis muscle in males with COPD. Eur Respir J 21: 273-278, 2003.

DEGENS H, BOSUTTI A, GILLIVER SF, SLEVIN M, VAN HEIJST A, WUST RC: Changes in contractile properties of skinned single rat soleus and diaphragm fibres after chronic hypoxia. Pflugers Arch 460: 863-873, 2010.

DUNLEAVY M, BRADFORD A, O'HALLORAN KD: Oxidative stress impairs upper airway muscle endurance in an animal model of sleep-disordered breathing. Adv Exp Med Biol 605: 458-462, 2008.

EDWARDS LM, MURRAY AJ, TYLER DJ, KEMP GJ, HOLLOWAY CJ, ROBBINS PA, NEUBAUER S, LEVETT D, MONTGOMERY HE, GROCOTT MP, CLARKE K, CAUDWELL XTREME EVEREST RESEARCH GROUP: The effect of high-altitude on human skeletal muscle energetic: P-MRS results from the Caudwell Xtreme Everest expedition. PLoS One 5: e10681, 2010.

EL-KHOURY R, O'HALLORAN KD, BRADFORD A: Effects of chronic hypobaric hypoxia on contractile properties of rat sternohyoid and diaphragm muscles. Clin Exp Pharmacol Physiol 30: 551-554, 2003.

FAUCHER M, GUILLOT C, MARQUESTE T, KIPSON N, MAYET-SORNAY MH, DESPLANCHES D, JAMMES Y, BADIER M: Matched adaptations of electrophysiological, physiological, and histological properties of skeletal muscles in response to chronic hypoxia Pflugers Arch 450: 45-52, 2005.

FULCO CS, CYMERMAN A, MUZA SR, ROCK PB, PANDOLF KB, LEWIS SF: Adductor pollicis muscle fatigue during acute and chronic altitude exposure and return to sea level. J Appl Physiol 77: 179-183, 1994.

FULCO CS, ROCK PB, MUZA SR, LAMMI E, BRAUN B, CYMERMAN A, MOORE LG, LEWIS SF: Gender alters impact of hypobaric hypoxia on adductor pollicis muscle performance. J Appl Physiol 91: 100-108, 2001.

GARNER SH, SUTTON JR, BURSE RL, MCCOMAS AJ, CYMERMAN A, HOUSTON CS: Operation Everest II: Neuromuscular performance under conditions of extreme simulated altitude. J Appl Physiol 68: 1167-1172, 1990.

GERTZ I, HEDENSTIERNA G, HELLERS G, WAHREN J: Muscle metabolism in patients with chronic obstructive lung disease and acute respiratory failure. Clin Sci Mol Med 52: 396-403, 1977.

GREEN HJ, SUTTON JR, CYMERMAN A, YOUNG PM, HOUSTON CS: Operation Everest II: adaptations in human skeletal muscle. J Appl Physiol 66: 2454-2461, 1989.

HAYOT M, RODRIGUEZ J, VERNUS B, CARNAC G, JEAN E, ALLEN D, GORET L, OBERT P, CANDAU R, BONNIEU A: Myostatin up-regulation is associated with the skeletal muscle response to hypoxic stimuli. Moll Cell Endocrinol 332: 38-47, 2011.

HIROFUJI C, ISHIHARA A, ITOH K, ITOH M, TAGUCHI S, TAKEUCHI-HAYASHI H: Fiber type composition of the soleus muscle in hypoxia-acclimatised rats. J Anat 181: 327-333, 1992.

HOPPELER H, FLUCK M: Plasticity of skeletal muscle mitochondria: structure and function. Med Sci Sports Exerc 35: 95-104, 2003.

HOPPELER H, VOGT M, WEIBEL ER, FLUCK M: Response of skeletal muscle mitochondria to hypoxia. Exp Physiol 88: 109-119, 2003.

HOWLETT RA, HOGAN MC: Effect of hypoxia on fatigue development in rat muscle composed of different fibre types. Exp Physiol 92: 887-894, 2007.

ISHIHARA A, ITOH K, OISHI Y, ITOH M, HIROFUJI C, HAYASHI H: Effects of hypobaric hypoxia on histochemical fiber-type composition and myosin heavy chain isoform component in the rat soleus muscle. Pflugers Arch 429: 601-606, 1995.

ITOH K, ITOH M, ISHIHARA A, HIROFUJI C, HAYASHI H: Influence of 12 weeks of hypobaric hypoxia on fiber type composition of the rat soleus muscle. Acta Physiol Scand 154: 417-418, 1995.

ITOH K, MORITANI T, ISHIDA K, HIROFUJI C, TAGUCHI S, ITOH M: Hypoxia-induced fibre-type transformation in rat hindlimb muscles. Eur J Appl Physiol 60: 331-336, 1990. 
KAYSER B, NARICI M, BINZONI T, GROSSI B, CERRETELLI P: Fatigue and exhaustion in chronic hypobaric hypoxia: Influence of exercising muscle mass. J Appl Physiol 76: 634-640, 1994.

LEVINE S, KAISER L, LEFEROVICH J, TIKUNOV B: Cellular adaptations in the diaphragm in chronic obstructive pulmonary disease. $N$ Engl J Med 337: 1799-1806, 1997.

MACDOUGALL JD, GREEN HJ, SUTTON JR, COATES G, CYMERMAN A, YOUNG P, HOUSTON CS: Operation Everest II: structural adaptations in skeletal muscle in response to extreme simulated altitude. Acta Physiol Scand 142: 421-427, 1991.

MADOR MJ, KUFEL TJ, PINEDA LA, SHARMA GK: Diaphragmatic fatigue and high-intensity exercise in patients with chronic obstructive pulmonary disease. Am J Respir Crit Care Med 161: 118-123, 2000.

MAN WD, KEMP P, MOXHAM J, POLKEY MI: Skeletal muscle dysfunction in COPD: clinical and laboratory observations. Review. Clin Sci (Lond) 117: 251-264, 2009.

MCGUIRE M, MACDERMOTT M, BRADFORD A: The effects of chronic episodic hypoxia on rat upper airway muscle contractile properties and fiber-type distribution. Chest 122: 1012-1017, 2002a.

MCGUIRE M, MACDERMOTT M, BRADFORD A: The effects of chronic episodic hypercapnic hypoxia on rat upper airway muscle contractile properties and fiber-type distribution. Chest 122: 1400-1406, 2002b.

MCGUIRE M, MACDERMOTT M, BRADFORD A: Effects of chronic intermittent asphyxia on rat diaphragm and limb muscle contractility. Chest 123: 875-881, 2003.

MCMORROW C, FREDSTED A, CARBERRY J, O'CONNELL RA, BRADFORD A, JONES JFX, O'HALLORAN KD: Chronic hypoxia increases rat diaphragm muscle endurance and sodium-potassium ATPase pump content. Eur Respir J 37: 1474-1481, 2011.

MORTOLA JP, NASO L: Electrophoretic analysis of contractile proteins of the diaphragm in chronically hypoxic rats. Am J Physiol 269: L371-L376, 1995.

POLKEY MI, KYROUSSIS D, HAMNEGARD CH, MILLS GH, GREEN M, MOXHAM J: Diaphragm strength in chronic obstructive pulmonary disease. Am J Respir Crit Care Med 154: 1310-1317, 1996.

POLKEY MI, KYROUSSIS D, HAMNEGARD CH, MILLS GH, HUGHES PD, GREEN M, MOXHAM J: Diaphragm performance during maximal voluntary ventilation in chronic obstructive pulmonary disease. Am J Respir Crit Care Med 155: 642-648, 1997.

SEGAL SS, FAULKNER JA: Temperature-dependent physiological stability of rat skeletal muscle in vitro. Am $J$ Physiol 248: 265-270, 1985.

SHIOTA S, OKADA T, NAITOH H, OCHI R, FUKUCHI Y: Hypoxia and hypercapnia affect contractile and histological properties of rat diaphragm and hind limb muscles. Pathophysiology 11: 223-230, 2004.

SILLAU AH, BANCHERO N: Effects of hypoxia on capillary density and fiber composition in rat skeletal muscle. Pflugers Arch 370: 227-232, 1977.

SKELLY JR, EDGE D, SHORTT CM, JONES JF, BRADFORD A, O'HALLORAN KD: Tempol ameliorates pharyngeal dilator muscle dysfunction in a rodent model of chronic intermittent hypoxia. Am J Respir Cell Mol Biol 46: 139-148, 2012.

SMITH K, MARSHALL JM: Physiological adjustments and arteriolar remodeling within skeletal muscle during acclimation to chronic hypoxia in the rat. $J$ Physiol 521: 261-272, 1999.

WHITTOM F, JOBIN J, SIMARD PM, LEBLANC P, SIMARD C, BERNARD S, BELLEAU R, MALTAIS F: Histochemical and morphological characteristics of the vastus lateralis muscle in patients with chronic obstructive pulmonary disease. Med Sci Sports Exerc 30: 1467-1474, 1998.

ZATTARA-HARTMANN MC, BADIER M, GUILLOT CH, TOMEI CH, JAMMES Y. Maximal force and endurance to fatigue of respiratory and skeletal muscles in chronic hypoxemic patients: The effects of oxygen breathing. Muscle Nerve 18: 495-502, 1995. 